\title{
THE IMPACT OF RURAL-URBAN MIGRATION ON UNDER-TWO MORTALITY IN INDIA
}

\author{
ROB STEPHENSON*, ZOE MATTHEWS† AND J. W. MCDONALD† \\ *Carolina Population Center, U niversity of $\mathrm{N}$ orth Carolina at Chapel $\mathrm{H}$ ill, \\ 123 W est Franklin Street, C hapel H ill, N C 27516, U SA and †D epartment of Social \\ Statistics, U niversity of Southampton, Southampton, S017 1BJ
}

\begin{abstract}
Summary. This paper examines the impact of rural-urban migration on under-two mortality in India, using data from the 1992/93 Indian N ational Family Health Survey. M ultilevel logistic models are fitted for mortality in three age groups: neonatal, early post-neonatal, and late post-neonatal and toddler. M igration status was not a significant determinant of mortality in any of the three age groups. Further analysis shows that a relationship between migration status and mortality exists when socioeconomic and health utilization variables are omitted from the models. The relationship between migration and mortality is thus explained by differences in socioeconomic status and use of health services between rural-urban migrant and nonmigrant groups. The selectivity of rural-urban migrants on socioeconomic characteristics creates mortality differentials between rural-urban migrants and rural non-migrants. Problems faced by migrants in assimilating into urban societies create mortality differentials between rural-urban migrants and urban non-migrants. These results highlight the need to target migrants in the provision of health services, and demonstrate that rural areas continue to have the highest levels of infant-child mortality. F urther research is needed to understand the health care needs of rural-urban migrants in order to inform the provision of appropriate health care.
\end{abstract}

\section{Introduction}

The level of rural-to-urban migration in India has traditionally been low (M ehta, 1990; Singh, 1992; Skeldon, 1986). The migration system in India is dominated by short distance rural-to-rural moves at the intra-district level. The past two decades, however, have witnessed an evolution in India's migration system, with the increasing importance of rural-to-urban migration. Between 1970 and 1990 the percentage of rural migrants with an urban destination doubled from $21 \%$ to $40 \%$ (Patil, 1993). R elative to other contemporary developing nations, however, the level of urbanization in India is low, with only $25 \%$ of the total 
population living in urban areas (International Institute for Population Sciences, 1994).

There exists a rural-urban dichotomy in the survival prospects of infants and children in India. The Indian National Family Health Survey (INFHS) 1992/93 reports that the infant mortality rate in urban areas was 56 per thousand live births, much lower than the rural rate of 85 per thousand live births. Similarly, the under-five mortality rate of urban areas at 74 per thousand live births is lower than the rural rate of 120 per thousand live births. Previous studies suggest that this dichotomy is a product of a combination of the differing child care practices and reproductive behaviour in urban and rural areas of India, and the differential access to health services between urban and rural areas (Gandotra, Das \& Day, 1982; Jain, 1979).

$G$ iven the presence of a clear urban-rural differential in infant and child survival in India, and the growth of the rural-urban migration stream in India's migration system, this paper poses the question: what is the impact on infant and child survival of migrating from the high mortality regime of rural areas to the relatively lower mortality regime of urban areas? The increasing importance of rural-urban migration in India leads to a greater number of people who are exposed to new environments and, potentially, to new influences on health and mortality. A $n$ understanding of the mortality risks associated with rural-urban migration has the potential to influence health policy and the provision of health services through an appreciation of the differential health needs of rural-urban migrants relative to non-migrant groups.

\section{B ackground}

Rural-urban migration in India

Internal migration in India has long been dominated by short distance rural-torural migration, with $60 \%$ of all movements occurring between rural areas at the intra-district level (M ehta, 1990; Skeldon, 1986; Singh, 1992). D uring the last three decades urbanization has increased rapidly with the percentage of the population living in urban areas increasing from 19.9\% to 25.7\% between 1971 and 1991 (Diwaker \& Qureshi, 1992). As a result more than 200 million people now live in the cities of India (approximately $25 \%$ of the total population), $30 \%$ of which live below the poverty line (Selvaraj \& Rao, 1993). In 1960 21\% of migrants from rural areas had an urban destination, by 1970 this had increased to $25.4 \%$ and by 1990 it had increased to more than 40\% (Patil, 1993). The consequences of this process have included the rapid growth of India's cities. The 1991 census showed that all of India's one million-plus cities have over one-third of their population made up of migrants, with the growth in rural areas (19.7\%) being much lower than in urban areas (46.4\%; Smita \& Chandna, 1991).

$\mathrm{M}$ igration to an urban destination has traditionally been male dominated, and at the interstate level all migration streams are male dominated (Skeldon, 1986). Gill (1981) notes that the ratio of migrating females to the total migrants varies inversely with the distance of migration. The participation of females in all migration streams has, however, increased since 1970 (Skeldon, 1986). This trend is particularly apparent in the rural-urban stream, where the sex ratio of migrants has declined from 119 males per 100 females in 1961-1971 to 100 males per 100 females in 1971-81 
(Skeldon 1986). This increase has been attributed to similar increases in rates of female participation in education and the labour force. Ferre \& Gulger (1983) note that the increasing number of female urban migrants has led to an increase in the number of females employed in unskilled work in urban areas of south India.

Sekhar (1993) notes that rural-urban migration in India involves those from both the low and high socioeconomic strata. For the poor in rural areas, urban-ward migration is a survival strategy against decreasing productivity, whereas for the rich, such migration is a strategy of economic accumulation (Sekhar, 1993). The propensity to migrate to an urban area is highest among educated people in rural areas (G reenwood, 1971), with the availability of employment in the major urban areas, particularly the mega-cities, providing the main attraction for migrants. Rural areas hold greater economic security for the unskilled and uneducated, for whom employment is scarce in the cities.

\section{M igration and mortality}

The relationship between migration and mortality is an area that has been little researched. $M$ any previous studies have focused on the biological or physiological consequences of migration to an urban area (Pollock, 1986; Bogin \& M acV ean, 1981; Padilla, 1980; Brody, 1973). Brockerhoff's (1995) analysis of D emographic and H ealth Survey data from seventeen countries demonstrates a three-level relationship between rural-urban migration and infant/child mortality. The survival prospects of ruralurban migrants were higher than those in their rural origin. The survival prospects of rural-urban migrants, however, remained below those of urban non-migrants (Brockerhoff, 1995). A similar pattern has been found when examining the use of health services among migrant and non-migrant groups (Tam, 1994; Zulkifili et al., 1994; Bender et al., 1993). Tam (1994) examined the association between rural-urban migration and maternal and child health service use in Bolivia and Peru, and showed that migrants increase their use of health services relative to their rural origin, but never replicate the utilization patterns of urban natives. Similar results have been shown in Malaysia (Zulkifili et al., 1994), Senegal ( $F$ assin \& J eannee, 1989) and Bolivia (Bender et al., 1993), with the level of use of modern health services by rural-urban migrants being consistently between the levels observed in the urban and rural non-migrant groups. Hence, both health outcomes and health-seeking behaviours demonstrate a three-level relationship, in which rural-urban migrants are between the outcomes/behaviours of their rural origin and urban destination.

Brockerhoff (1995) suggests that there are three groups of children that can be affected to differing degrees by the process of rural-to-urban migration: those children left behind in the rural areas; those who accompany their mothers on migration; and those born after migration has taken place. Each of these groups has a different survival prospect, with those remaining in the rural areas and those born either 2 years before or after migration holding the greatest mortality risks. Children born more than 2 years after migration have the lowest rates of mortality, and there appears to be no decline in mortality rates beyond this with duration of residence in urban areas (Brockerhoff, 1990). Children born more than 2 years after migration still do not manage to achieve the low mortality rates of urban non-migrants. 
Two hypotheses have been suggested to explain the differential health outcomes between migrant and non-migrant groups. Firstly, migrant selectivity, in which the process of rural-urban migration is selective for those with characteristics that predispose them to particular health behaviours (for example, higher levels of education). The increased survival prospects among the children of rural-urban migrants is determined by characteristics that also make them the most likely to migrate out from rural areas (Brockerhoff \& Eu, 1993). U yanga (1983) suggests that this creates a migrant personality, in which those migrating between rural and urban areas are more receptive to the use of modern health facilities, and thus have better health outcomes than rural non-migrants. This, coupled with the increased availability of health services and a potential for greater socioeconomic status in urban areas, produces health differentials between rural-urban migrant and rural non-migrant groups (U yanga, 1983).

The differential health outcomes between rural-urban migrants and urban non-migrants are suggested to be the product of migrant difficulties in assimilating into the new urban environment (Goldsheider, 1989; R ichman et al., 1987). M igrant assimilation refers to the extent to which a migrant assimilates economically, socially and culturally into the host society (Berry, 1992; Goldscheider, 1989). A migrant's successful assimilation into their new urban environment depends not only on the behaviour and social mobility of the migrant, but also on the receptivity of the urban society (Brockerhoff, 1995). The concentration of migrants in low income and informal employment sectors often creates a distinct underclass, preventing migrants from fully assimilating into urban society. A bu-Loghod (1961) notes the importance of social institutions in aiding the assimilation of migrants into the host population. Such social institutions include community groups, health services, and family members already living in the host area, which can provide information to allow the migrant to adapt to their new urban environment. The inherent cohesiveness of migrant populations, and the continued pattern of rural social institutions in urban areas, may result in a lack of social interaction between the migrant and urban populations. The failure of migrants to assimilate into their new urban environment can lead to the continuation of traditional rural medical practices among migrant groups and the under-utilization of modern health services (D avidson, 1983; U yanga, 1983). The concentration of migrants in the lower socioeconomic strata, their under-utilization of health services and the continuation of rural medical practices results in a mortality differential between rural-urban migrants and urban non-migrants.

This paper examines the impact of rural-urban migration on under-two mortality in India, and examines the pathways through which migration may act to influence mortality. The processes of migrant selectivity and assimilation are examined as potential explanations for mortality differentials between rural-urban migrant and non-migrant groups.

\section{D ata and methods}

The data set for this analysis is the 1992/93 Indian N ational Family Health Survey (IN FHS). The target population for the survey was ever-married women aged 13-49, 
with data collected at three levels: individual, household and village. D ata were collected for each of the twenty-four states of India and the National Capital Territory of Delhi (International Institute for Population Sciences, 1994). In order to ensure that enough migrants are included in the analysis sample, the data for the whole of India are used, such that a sample size of 89,777 women is analysed. To reduce the influence of recall bias on the reporting of children's age at death, the analysis is restricted to children born in the 5 years prior to the survey. Hence the analysis refers to births during the period 1988-1992.

The analysis of mortality concentrates on the under-two-year age group, divided into three intervals: neonatal (less than one month), early post-neonatal (1-7 months) and late post-neonatal and toddler (8-24 months). The reasons for this division are two-fold. Firstly, the data from the IN F HS (1992/93) display evidence of age-heaping in the mother's reporting of the age of death of the child. To surmount these problems age groups have been chosen that include the age heaps: the 7-24 month category includes the heaps at 6, 12 and 18 months. The second reason for the choice of mortality periods is the recognition of the changing determinants of mortality with age of the child.

This analysis applies a three-level multi-level logistic regression model in each of the mortality periods: child (level one), woman (level two) and primary sampling unit (PSU; level three), with a binary mortality outcome (coded 1 if the child died). The IN F HS (1992/93) collected complete birth histories from each woman, such that many women contribute more than one birth to the sample, so children are naturally clustered within women. In addition to this natural clustering of children within mothers, the sample design of the IN F HS (1992/93) imposes the clustering of women within primary sampling units. The three-level logistic model can be written as follows:

$$
\text { logit }\left(p_{i j k}\right)=x_{i j k}^{\prime} \beta+u_{j k}+v_{k} \text {, }
$$

where $p_{i j k}$ is the probability of dying for the ith child in the jth family in the kth cluster, $x^{\prime}{ }_{i j k}$ is a vector of covariates corresponding to the ith child in the $j$ th family in the kth cluster, $\beta$ is a vector of unknown parameters, $u_{j k}$ is the random effect at the woman level, and $v_{k}$ is the random effect at the primary sampling unit level. $A$ significant random component $\left(u_{i j}, v_{k}\right)$ indicates that there is a significant variation in the risk of death between families or clusters, suggesting unobserved familial or cluster-level heterogeneity. The models are estimated using the first-order predictive quasi-likelihood estimation procedure, which corrects for the downward bias in standard errors and overstatement of the significance of the independent variables due to the clustering of observations within units.

The IN F HS (1992/93) contains a range of variables that can be used as potential explanatory factors for infant and child mortality, including factors relating to pregnancy and childbirth, socioeconomic status of the individual and household, environmental characteristics of the household, and the utilization of health services. The INFHS (1992/93) did not collect data on household income. A standard of living index was calculated using variables relating to household socioeconomic characteristics, household environmental conditions and the ownership of goods, and is used in the analysis as a composite index to represent the socioeconomic status of the 
household. The standard of living index was calculated by giving each of categories of the variables relating to household environmental conditions and ownership of goods a score according to the relative desirability (e.g. piped water into the house was given a higher score than the use of well water). The scores were then summed and divided into five categories to represent different socioeconomic groups.

The variables that were significantly related to mortality in the multi-level logistic models are then grouped into four categories: biodemographic, socioeconomic, health care utilization and geographic. For each of the three mortality periods five further models are fitted, each one regressing migration status and one of the four categories of the determinants of mortality against mortality status. This modelling process is illustrated in Table 1. M odel 1 in each mortality period includes only migration status as an explanatory variable, whilst Model 2 includes migration status and biodemographic variables as explanatory variables. Thus, each of the five models fits migration status and a different category of mortality determinants against mortality status. This modelling strategy is intended to allow a comparison of the influence of each of the different sets of factors on the relationship between migration and mortality.

\section{The migrant population}

F or the purpose of this research, a migrant is defined as a respondent who has moved between any combination of rural and urban areas in the 10 years prior to the survey. This definition was used partly due to the limited migration information collected in the INFHS (1992/93). M igration histories were not collected, and thus questions relating to the number of years spent in the respondent's current place of residence, and the type of both the previous and current place of residence (rural or urban), were used to establish migration status. U sing this information it was possible to identify four migration streams: rural-to-rural, urban-to-urban, rural-to-urban and urban-to-rural. This definition of a migrant captures only the last migration made by each respondent in the 10 years prior to the survey, and may omit those involved in circular migration. A lthough there are alternative sources of migration data for India (the Census and the Sample R egistration System), neither of these includes information on other factors that can be used to examine under-two morality (socioeconomic and health care utilization). The IN FHS (1992/93) represents the best opportunity to examine the relationship between migration and mortality in India whilst controlling for other correlates of mortality.

Table 2 displays the distribution of the three analysis samples by migration status. The cases are the children of migrant and non-migrant women. A variable was created categorizing the sample into urban non-migrants, rural non-migrants and rural-to-urban migrants. M igrants taking part in the remaining streams (rural-rural, urban-urban and urban-rural) are now referred to as 'other migrants'. A pproximately $8 \%$ of the analysis samples are rural-urban migrants, compared with approximately $10 \%$ in the general Indian population in 1990 (M ehta, 1990).

Table 3 displays the neonatal and post-neonatal mortality rates for each of the age intervals under analysis by migration status. The mortality of the rural-urban migrants is lower than that of the rural non-migrants in all three mortality intervals. 
M igration and mortality in India

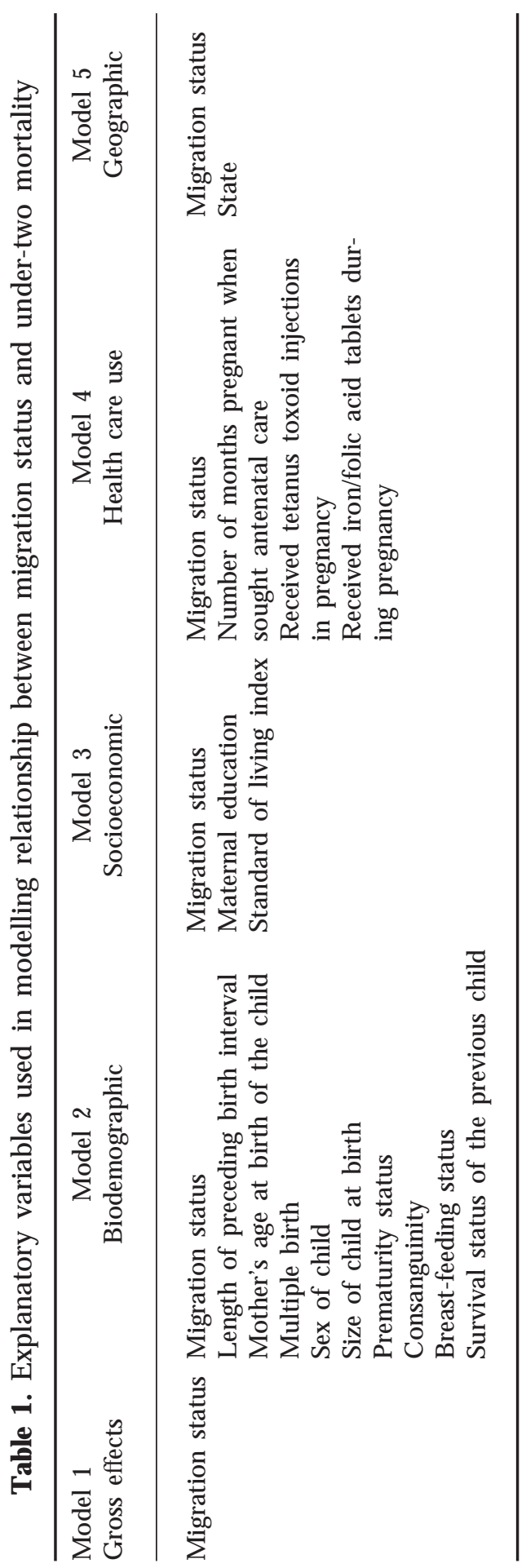


Table 2. Distribution of analysis sample by migration status

\begin{tabular}{lccc}
\hline & N eonatal & Early post-neonatal & Late post-neonatal \& toddler \\
\hline U rban non-migrant & $6731(11 \cdot 0)$ & $5809(11 \cdot 2)$ & $3925(11 \cdot 8)$ \\
R ural non-migrant & $21,360(34 \cdot 9)$ & $18,107(35 \cdot 0)$ & $12,322(37 \cdot 1)$ \\
R ural-urban migrant & $4929(8 \cdot 1)$ & $4205(8 \cdot 1)$ & $2613(7 \cdot 9)$ \\
Other migrant* & $28,111(46 \cdot 0)$ & $23,561(45 \cdot 6)$ & $14,371(43 \cdot 2)$ \\
Total & $61,131(100 \cdot 00)$ & $51,682(100 \cdot 00)$ & $33,213(100 \cdot 00)$ \\
\hline
\end{tabular}

*'Other migrant' refers to remaining combinations of rural and urban: rural-rural, urbanurban and urban-rural.

Figures in parentheses are percentages.

Table 3. Neonatal and post-neonatal mortality rates by migration status

\begin{tabular}{lccc}
\hline & N eonatal & $\begin{array}{c}\text { Early } \\
\text { post-neonatal }\end{array}$ & $\begin{array}{c}\text { Late } \\
\text { post-neonatal \& toddler }\end{array}$ \\
\hline Total rate (per thousand live births) & 43.6 & 19.0 & 26.4 \\
M igration status & & & \\
U rban non-migrant & 34.1 & 13.2 & 17.8 \\
Rural-urban migrant & 34.6 & 16.8 & 21.8 \\
Rural non-migrant & 45.5 & 20.5 & 32.3 \\
Other migrant & 46.9 & 19.5 & 24.6 \\
\hline
\end{tabular}

The rural-urban migrant mortality is above that of the urban non-migrants in each of the three intervals. This indicates that the migration-mortality relationship found by Brockerhoff (1995), in which the mortality of migrants lies between that of the origin and destination, may also be apparent in India. The mortality differentials between migrants and urban non-migrants are greater after the neonatal period, demonstrating that it is only in the neonatal period that the children of rural-urban migrants gain most of the benefits of urban residence.

\section{R esults}

The influence of urban/rural residence on mortality

$\mathrm{R}$ ural/urban residence was entered into the models as an explanatory variable to test the influence of place of residence on mortality. When rural/urban residence was entered as the only explanatory variable, rural areas showed greater odds of mortality in all three age groups (neonatal $1 \cdot 28$, post-neonatal $1 \cdot 32$, late post-neonatal and toddler 1.43). The relationship between rural/urban residence and mortality remains significant when controlling for the socioeconomic and biodemographic characteristics 
of the children. When variables indicating environmental conditions and the use of maternal health services are included in the model there is no longer a significant relationship between mortality and rural/urban residence. Place of residence is thus an important correlate of under-two mortality, and the differences between rural and urban areas are explained by differential use of maternal health care and environmental conditions, reflecting the differing service regimes and socio-environmental infrastructures of rural and urban areas.

The influence of migration on under-two mortality

Tables 4 presents the results of the multi-level modelling of under-two mortality. The discussion will concentrate on the importance of the migration status variable as a determinant of under-two mortality. M igration status is not a significant correlate of mortality in any of the three mortality periods analysed when controlling for other determinants of mortality. Interaction terms were fitted between migration status and each of the other determinants of mortality, but none of these was significant. The analysis also used variables relating to the duration of residence in urban areas, the timing of migration in relation to the birth of the child (before, after or in the same year) and the timing of migration in relation to marriage (before, after or in the same year). $\mathrm{N}$ one of these variables was significantly related to mortality in any of the three periods analysed. The insignificance of length of time in urban areas shows that there is no 'dose-response' relationship between migration and mortality.

Model 1, which includes migration status as the only explanatory variable, displays a significant relationship between migration status and both neonatal and late post-neonatal and toddler mortality. In the neonatal period, rural non-migrants have a $33 \%$ greater odds of experiencing mortality than rural-urban migrants. There is no statistically significant difference in the odds of neonatal mortality between the urban non-migrant and rural-urban migrant groups. In the late post-neonatal and toddler period rural non-migrants have a $50 \%$ greater odds of experiencing mortality when compared with rural-urban migrants, whilst urban non-migrants have a $18 \%$ lower odds of experiencing mortality than the rural-urban migrants. There is no significant relationship between migration status and early post-neonatal mortality.

M odel 2 introduces the biodemographic determinants of mortality into the model, and this process has no effect on the significant relationship between migration status and neonatal mortality. The relationship between migration status and early post-neonatal mortality is not significant. In the late post-neonatal and toddler periods the significant difference in the odds of mortality between the urban non-migrants and rural-urban migrants is no longer apparent, although the difference in the odds of mortality between rural-urban migrants and rural non-migrants remains significant. Whilst the relationship between migration and mortality among rural-urban migrants and rural non-migrants is independent of biodemographic factors, such factors are important in explaining the mortality differentials found between rural-urban migrants and urban non-migrants.

The introduction of the socioeconomic determinants of mortality in Model 3 results in the disappearance of a statistically significant relationship between migration status and mortality in the neonatal and late post-neonatal and toddler groups. The 
Table 4. Odds ratios, with $95 \%$ confidence intervals, for multilevel logistic models of neonatal, post-neonatal, and late post-neonatal and toddler mortality

\begin{tabular}{|c|c|c|c|}
\hline Variable & N eonatal & $\begin{array}{c}\text { Early } \\
\text { post-neonatal }\end{array}$ & $\begin{array}{c}\text { Late } \\
\text { post-neonatal \& toddler }\end{array}$ \\
\hline \multicolumn{4}{|l|}{ M igration status } \\
\hline Rural-urban migrant & 1.00 & 1.00 & 1.00 \\
\hline U rban non-migrant & $1.09(0.87,1.30)$ & $0.95(0.60,1.29)$ & $0.93(0.55,1.30)$ \\
\hline Rural non-migrant & $1.12(0.93,2.05)$ & $0.77(0.48,1.06)$ & $1.19(0.87,1.50)$ \\
\hline Other migrant & $1.15(0.96,1.34)$ & $1.06(0.78,1.33)$ & $1.01(0.70,1 \cdot 31)$ \\
\hline \multicolumn{4}{|l|}{$M$ aternal age } \\
\hline$<19$ & 1.00 & 1.00 & 1.00 \\
\hline $20-24$ & $0.85(0.73,0.96)$ & $0.84(0.66,1.01)$ & $0.93(0.77,1.09)$ \\
\hline $25-29$ & $0.93(0.79,1.06)$ & $0.75(0.52,0.97)$ & $0.95(0.32,1.27)$ \\
\hline $30-34$ & $1.21(1.04,1.38)$ & $0.75(0.46,1.03)$ & $1.05(0.89,1.21)$ \\
\hline $35+$ & $1 \cdot 17(1 \cdot 05,1 \cdot 38)$ & $1.15(0.82,1.47)$ & $1.08(0.74,4.12)$ \\
\hline \multicolumn{4}{|l|}{ Previous birth interval } \\
\hline$<18$ months & 1.00 & 1.00 & 1.00 \\
\hline 18-36 months & $0.46(0.33,0.58)$ & $0.47(0.28,0.66)$ & $0.52(0.33,0.71)$ \\
\hline$>36$ months & $0.34(0.19,0.48)$ & $0.32(0.09,0.54)$ & $0.31(0.07,0.54)$ \\
\hline First birth & $0.75(0.61,0.88)$ & $0.46(0.24,0.67)$ & $0.42(0.19,0.64)$ \\
\hline \multicolumn{4}{|l|}{ Sex of child } \\
\hline M ale & $1 \cdot 00$ & 1.00 & 1.00 \\
\hline F emale & $0.84(0.76,0.92)$ & $0.99(0.85,1.12)$ & $1.38(1.24,1.51)$ \\
\hline \multicolumn{4}{|l|}{ Size of child at birth } \\
\hline L arge & 1.00 & 1.00 & 1.00 \\
\hline A verage & $0.43(0.32,0.52)$ & $0.63(0.46,0.79)$ & $0.46(0.28,0.63)$ \\
\hline Small & $0.96(0.84,1.07)$ & $1.25(1.06,1.43)$ & $0.74(0.53,0.94)$ \\
\hline \multicolumn{4}{|l|}{ Premature birth } \\
\hline No & 1.00 & 1.00 & 1.00 \\
\hline Y es & $8.28(8 \cdot 14,8.41)$ & $2 \cdot 33(2 \cdot 01,2 \cdot 64)$ & $2 \cdot 14(1 \cdot 75,2 \cdot 52)$ \\
\hline Don't know & $1 \cdot 71(1 \cdot 18,2 \cdot 23)$ & $1.27(0.42,2 \cdot 11)$ & $1.60(0.81,2 \cdot 38)$ \\
\hline \multicolumn{4}{|l|}{ Ever breast-fed } \\
\hline Y es & na & 1.00 & na \\
\hline No & na & $5.06(4.79,5.32)$ & na \\
\hline \multicolumn{4}{|l|}{ Time of weaning } \\
\hline$<6$ months & na & na & 1.00 \\
\hline$>6$ months & na & na & $1.96(1 \cdot 78,2 \cdot 13)$ \\
\hline $\mathrm{N}$ ot breast-fed & na & na & $1.89(1.37,2.40)$ \\
\hline \multicolumn{4}{|l|}{ M aternal education } \\
\hline Illiterate & 1.00 & 1.00 & 1.00 \\
\hline Primary-middle & $0.80(0.66,0.93)$ & $0.72(0.53,0.90)$ & $0.63(0.40,0.86)$ \\
\hline Higher+ & $0.57(0.36,0.77)$ & $0.41(0.03,0.79)$ & $0.25(0.13,0.37)$ \\
\hline
\end{tabular}


Table 4. Continued

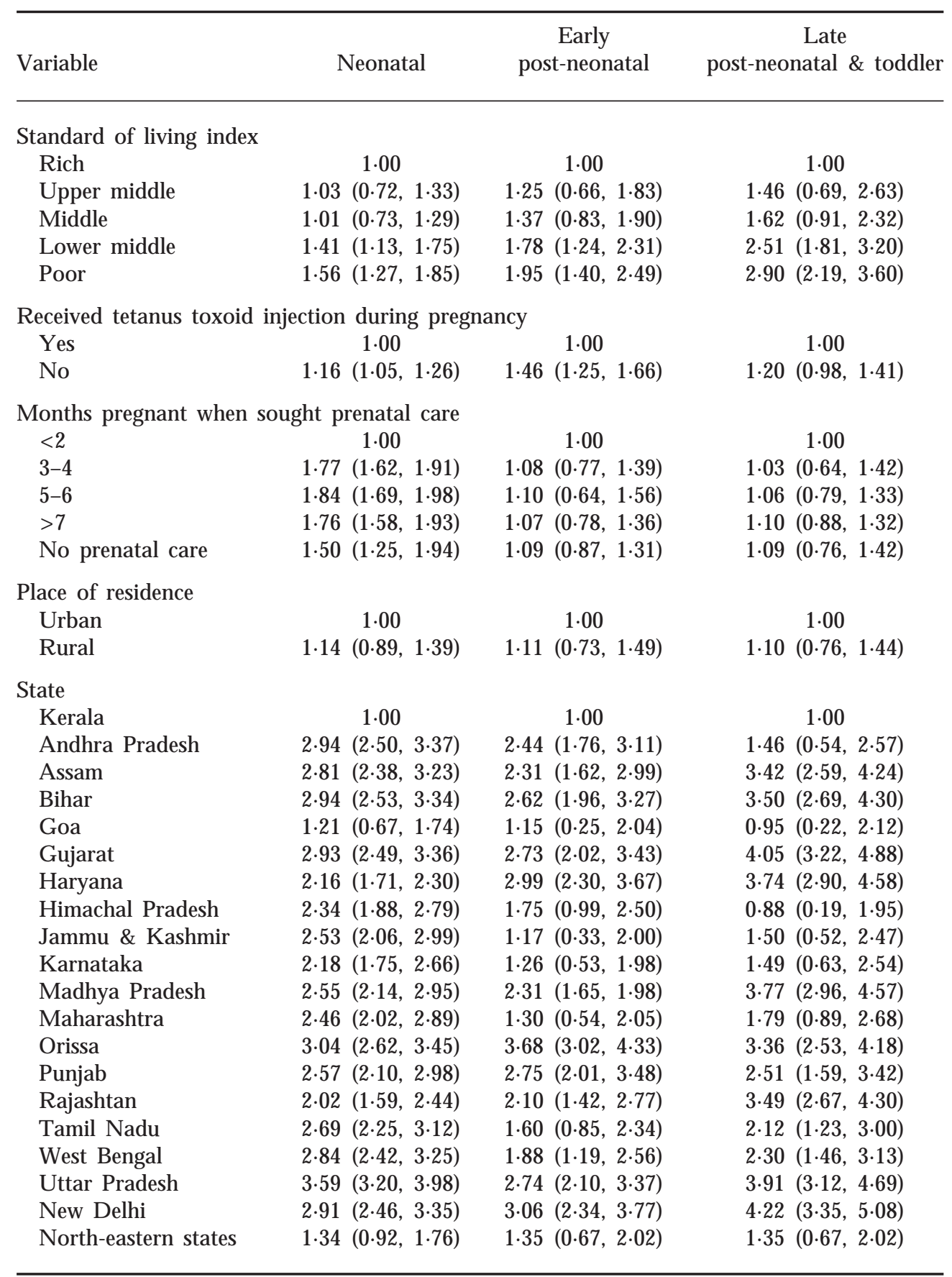

na: variable not included in the model. 
Table 5. Beta coefficients and standard errors of random effects terms in multilevel logistic models of neonatal, post-neonatal, and late post-neonatal and toddler mortality

\begin{tabular}{lccc}
\hline Level & N eonatal & Early post-neonatal & Late post-neonatal \& toddler \\
\hline $\begin{array}{l}\text { Household } \\
\text { Primary sampling unit }\end{array}$ & $0.459(0.097)$ & $0.229(0.239)$ & $0.017(0.214)$ \\
& $0.072(0.032)$ & $0.077(0.071)$ & $0.214(0.079)$ \\
\hline
\end{tabular}

direction of the relationships remains similar to that seen in Model 1 , yet the relationship is no longer significant at the $5 \%$ level. The relationship between rural-urban migration and neonatal and late post-neonatal and toddler mortality is partly explained by differences in the distribution of the socioeconomic determinants of mortality between migrant and non-migrant groups.

M odel 4 introduces variables associated with maternal health care utilization into the model, and there is no longer a significant relationship between migration status and neonatal or late post-neonatal and toddler mortality. The mortality differentials present in these two groups are thus partly explained by the unequal distribution of maternal health care variables between migrant and non-migrant groups.

$M$ odel 5 introduces the state in which the respondent lives into the model, in order to examine the effects that state-level variations in cultural influences on mortality and service availability have on the relationship between migration and under-two mortality. The significant relationships between migration status and neonatal and late post-neonatal and toddler mortality remain after the introduction of state into the model, suggesting that the impact of migration on mortality is independent of the state in which the respondent lives.

U nobserved heterogeneity in mortality

Table 5 shows the household- and primary sampling unit- (PSU) level random effects terms for the three mortality periods. Significant household-level variation in the odds of mortality was found only in the neonatal period. It is likely that the household-level variance reflects maternal heterogeneity: that is, the propensity for children from the same mother to experience neonatal mortality due to shared genetic, parental and environmental characteristics, beyond those controlled for in the model. Significant PSU -level variation was found in both the neonatal and late post-neonatal and toddler periods. A PSU represents a sample of 30 households in rural areas and 20 households in urban areas. The place of residence (rural/urban) was not significant once socioeconomic and maternal health care variables were controlled for, yet the presence of PSU variation in mortality indicates that there are more local-level variations in mortality. The presence of PSU variation in mortality after controlling for socioeconomic and maternal health care factors may reflect local-level variations in accessibility to child health facilities, child care practices and environmental conditions. 
$M$ igrant selectivity

In both the neonatal and late post-neonatal and toddler periods, rural nonmigrants had significantly higher odds of mortality relative to rural-urban migrants, yet these relationships were no longer significant once maternal education was controlled for. Higher levels of maternal education have long been shown to be associated with lower levels of infant and child mortality (Cleland, 1990; Cleland \& van G inneken, 1988; Caldwell, 1986; Caldwell \& M CD onald, 1982), a relationship that operates through a range of pathways, including greater access to services and resources and increased personal autonomy and power in decision-making. The mortality differentials between rural non-migrants and rural-urban migrants are created not necessarily through the process of migration, but through the greater propensity for those with higher educational attainment to migrate between rural and urban areas. The mortality differentials between those with differing levels of education may be apparent within rural areas, although the process of migration to an urban area may increase mortality differentials between educational groups through the exposure to a new service environment and social infrastructure. The greater powers of autonomy and decision-making afforded to those with higher levels of education may be put into practice in urban areas with greater service availability, rather than be restricted by the poor service availability environments of rural areas.

Change in environments

Rural non-migrants had significantly greater odds of both neonatal and late post-neonatal and toddler mortality than rural-urban migrants until the standard of living index was included in the models. Mortality differentials between these two groups are a product of differences in environmental and socioeconomic conditions experienced by rural non-migrant and rural-urban migrant groups. The rural non-migrant group is characterized by employment in the agricultural sector $(80 \%)$, residence in informal housing (63\%) and dependence on informal sanitation facilities (49\%). The rural-urban migrant group is characterized by employment in the service/production sector (47\%), residence in semi-pucca or pucca housing $(69 \%)$ and the use of piped water sources (77\%). These differences in living environments between rural non-migrants and rural-urban migrants may be the result of two factors: the educational selectivity of the rural-urban migrant group, which affords them greater employment opportunities; and the superior infrastructure of urban areas, which increases the availability of formal housing and sanitation facilities relative to rural areas. The introduction of variables indicating the uptake of maternal health care services also resulted in the lack of a significant mortality differential between rural-urban migrants and rural non-migrants in the neonatal and late post-neonatal and toddler groups. This reflects the differing availability of maternal health care services between rural and urban areas. The provision, and consequently the uptake, of maternal health care in rural India is inferior to that found in urban areas (Prasad \& Somayjulu, 1992). Rural-urban migrants thus migrate between two very different environments, with different service availabilities, environmental conditions and social infrastructures, which together with the educational selectivity of rural-urban migration, act to create mortality differentials between the rural non-migrant and rural-urban migrant groups. 
$M$ igrants' social and economic assimilation

In the late post-neonatal and toddler periods the rural-urban migrant group have significantly higher odds of mortality than the urban non-migrant group. This relationship is explained by the inclusion of socioeconomic and health care utilization variables into the model. The housing of rural-urban migrants is characterized by informal dwellings on the outskirts of urban areas, often lacking formal health and sanitation facilities (Brockerhoff, 1995). The environmental characteristics of such informal housing have been shown to be detrimental to child survival prospects (D hanalakshmi \& M urphy, 1993). The influence of environmental conditions on child mortality has been emphasized in studies that show level of overcrowding and lack of sanitation facilities to be major determinants of child survival prospects (Timaeus $\&$ L ush, 1995). The siting of migrant housing has also been shown to affect child and infant mortality, the economic inferiority of migrants forcing them to occupy land more subject to physical and chemical hazards posed by the proximity of heavy industry, hence increasing the risks of respiratory infections (Brockerhoff, 1995). Prasad \& Somayjulu (1992) demonstrated that the slum dwellers of Calcutta and M umbai experienced a severe lack of government health services. Although these cities are better equipped in terms of health services than the rural areas, the primary health care services appeared to be inaccessible to the poorer sectors of the urban society, in which migrants are often concentrated.

The late post-neonatal and toddler mortality differentials between urban nonmigrants and rural-urban migrants are explained by differences in the standards of living and utilization of maternal health services between by the two groups. The rural-urban migrant group is concentrated in the lower economic strata, with $46 \%$ in the bottom two groups of the standard of living index, compared with $36 \%$ of the urban non-migrant group. Only $2 \%$ of the rural-urban migrant group are in the highest group of the standard of living index, compared with $9 \%$ of the urban non-migrant group. These disparities between rural-urban migrants and urban non-migrants indicate that migrants have failed to assimilate fully into their new urban environment. Despite educational levels that are similar to the urban non-migrant group, rural-urban migrants are concentrated in the lower economic strata. The economic and social disadvantages that this affords act to create mortality differentials between rural-urban migrants and urban non-migrants. This process is only in operation in the oldest age group, reflecting the importance of socioeconomic determinants of mortality at older ages.

\section{Conclusion}

$\mathrm{R}$ ural/urban residence has a significant effect on mortality in India, independent of the characteristics of the children, yet this relationship disappears with the introduction of environmental and health care variables. Place of residence is thus an important correlate of under-two mortality, and the relationship is explained by the differing social, environmental and health care infrastructures of rural and urban areas. $M$ igration between rural and urban areas has no effect on mortality when socioeconomic, health care and biodemographic factors are controlled for. When migration 
status is used as the only explanatory variable, there are significant differences in the odds of mortality in the neonatal and late post-neonatal and toddler groups. F urther modelling shows that these mortality differentials disappear when socioeconomic and health care variables are controlled for. The results suggest two processes are acting to create mortality differentials between migrant and non-migrants. The selectivity of rural-urban migrants on factors that predispose them to lower levels of infant/child mortality acts to create neonatal mortality differentials between rural-urban migrants and rural non-migrants. Problems faced by rural-urban migrants in assimilating into their new urban environment (as indicated by their lower socioeconomic position relative to urban non-migrants) results in rural-urban migrants having higher odds of mortality than urban non-migrants. This process is only in operation at older ages (8-24 months), reflecting the greater influence that socioeconomic factors have on mortality at older ages.

The results show that the three-level relationship between rural-urban migration and mortality, as identified by Brockerhoff (1995), is present in late post-neonatal and toddler mortality in India, but does not adequately explain the relationship between rural-urban migration and neonatal mortality. Rural-urban migrants do not have significantly different levels of neonatal mortality to urban non-migrants, indicating that migration to an urban area increases the survival prospects of neonates to the extent that they adopt urban rates of mortality. Rural-urban migrants experience higher levels of late post-neonatal and toddler mortality, a product of their inferior socioeconomic situation relative to urban non-migrants. These results highlight the need to target migrant groups within urban areas in the provision of health care services, and demonstrate that rural areas continue to experience the highest levels of infant/child mortality. F urther research is needed to understand the health care needs of migrants in urban areas in order to inform the provision of appropriate health care.

\section{A cknowledgments}

The authors would like to thank the Economic and Social Research Council of the U nited K ingdom (award number R 00429634316) for financially supporting a substantial proportion of the work reported in this paper.

\section{R eferences}

A Bu-L oghoD, J . (1961) M igrant adjustment to city life: The Egyptian case. A m. J . Sociol. 67(1), 22-32.

Bender, D. E., R IVERA, T \& \& M ADONNA, D . (1993) R ural origin as a risk factor for maternal and child health in peri-urban Bolivia. Social Sci. Med. 37(11), 1345-1349.

BERRY, J. W. (1992) A cculturation and adaptation in a new society. Int. M igration 30, 69-84.

Bogin, B. \& M ACVEAN, R. B. (1981) Biosocial effects of urban migration on the development of families and children in Guatemala. Am. J. publ. H Ith 71, 1373-1377.

BrockerhofF, M . (1990) Rural to urban migration and child survival in Senegal. Demography 27(4), 601-616. 
B rockerhofF, M . (1995) Child survival in big cities: The disadvantages of migrants. Social Sci. M ed. 40(10), 1371-1383.

BrockerhofF, M \& \& EU, H. (1993) Socio-economic and demographic determinants of female rural-urban migration in sub-Saharan A frica. Int. M igration R ev. 27(103), 557-577.

Brody, E. B. (1973) The Lost Ones: Social Forces and M ental Illness in Rio de J aneiro. Int. U niversities Press, $\mathrm{N}$ ew Y ork.

Caldwell, J. C. (1986) Routes to low mortality in poor countries. Popul. Dev. Rev. 12(2), 171-220.

CALdwell, J. C. \& M CD ONALD, J. W. (1982) Influence of M aternal Education on Infant and Child M ortality: Levels and Causes. IU SSP, M anila.

Cleland, J. G. (1990) M aternal education and child survival: further evidence and explanations. In: What We Know about Health Transition: The Cultural, Social and Behavioural Determinants of $\mathrm{H}$ ealth (Proceedings of an International Workshop, Canberra, M ay 1989), pp. 400-419. Edited by J. C. Caldwell, S. Findley, P. Caldwell, G. Santow, W. Cosford, J. Braid \& D. Brorers-F reeman. A ustralian $\mathrm{N}$ ational University, $\mathrm{H}$ ealth Transition Centre, Health Transition Series N o. 2. Canberra, A ustralia.

Cleland, J. G. \& van Ginnenken, J. K. (1988) M aternal education and child survival in developing countries: the search for pathways of influence. Social Sci. M ed. 27(12), 1357-1368.

D Avidson, J. (1983) The survival of traditional medicine in a Peruvian Barriada. Social Sci. M ed. 17(17), 1271-1280.

D hanalakshmi, G. T. \& M URPhy, M. S. (1993) Environmental correlates of child morbidity in A ndhra Pradesh. J. Fam. W elfare 39(3), 18-27.

D IWAKer, A . \& QuREshi, M . H . (1992) Demographic processes of urbanization in D elhi. Popul. Geogr. 4(1-2), 27-36.

F ASSIN, D. \& JEANNEE, E. (1989) Immunisation coverage and social differentiation in urban Senegal. A m. J. publ. HIth 79, 509-511.

F ERRE, M . M \& \& G ULGER, J . (1983) The participation of women in the urban labour force and in rural-urban migration in India. Demography India 12(2), 194-213.

G andotra, M. N., D AS, N. \& Dey, D. (1982) Infant M ortality and its Causes. Himalaya Publishing House, Bombay, India.

G ILL, M. S. (1981) Patterns of migration in an under-developed tract: Hissar District of H aryana, 1951-1971. Geogr. Rev. India 43(2) 105-121.

GolDSCHEIDER, C. (1989) Migration and social structure: analytic issues and comparative perspectives in developing nations. In: Demography as an Interdiscipline, pp. 56-78. Edited by J. M. Stycos. Transaction Publications, Brunswick, Oxford.

G REENwoOD, M. J . (1971) The influence of family and friends on geographic labour mobility in a less developed country. The case of India. Rev. region. Stud. 3(1), 27-36.

International Institute for Population Sciences (1994) National Family Health Survey 1992-93. India Introductory Report. Bombay.

J AIN, S. P. (1979) Levels and differentials of infant and child mortality: Determinants and demographic impact. In: Demographic and Socio-economic Aspects of the Child in India. Edited by K. Srinivasan, P. C. Saxena \& T. K anitkar. Himalaya Publishing H ouse, Bombay, India.

M EнTA, S. (1990) Spatial mobility in India: Evolving patterns, emerging issues and implications. Popul. Geogr. 12(1\&2), June-D ecember.

Padilla, A. (1980) The role of cultural awareness and ethnic loyalty in acculturation. In: A cculturation: Theory, M odels and Some N ew Findings. Edited by A. Padilla. A A A S Selected Symposium 30, Westview Press, CO, USA. 
Patil, R. C. (1993) The process of urbanization in India, 1971-1991. J. Fam. Welfare 39(1) 44-51.

Pollock, G. H. (1986) The mourning-liberation process and migration: voluntary and coerced. Paper presented at the Third International Symposium of the American Society of $\mathrm{H}$ ispanic Psychiatrists, M erida, M exico, 1986. Cited in: Richman, J. A ., Gaviria, M., Flaherty, J. A., Birz, S. \& Wintrob, R. (1987) The process of acculturation: theoretical perspectives and an empirical investigation in Peru. Social Sci. M ed. 25, 839-947.

Prasad, D. V. \& Somayjulu, U. V. (1992) A comparative study of the accessibility of health and family welfare among slum dwellers. J. Fam. W elfare 38(4), 15-18.

R ichman, J. A ., G aviria, M ., F Laherty, J. A., Birz, S. \& W introb, R. (1987) The process of acculturation: theoretical perspectives and an empirical investigation in Peru. Social Sci. M ed. 25, 839-947.

SEKHAR, T. V. (1993) M igration selectivity from rural areas: evidences from Kerala. Demography India 22(2), 191-202.

SelvaraJ, K. G. \& R AO, P. S. (1993) H ousehold migration - urbanisation and consequences. Demography India 22(2) 203-210.

SiNGH, J. P. (1992) M igration in India: a review. A sian and Pacific M igration J . 1(1), 168-192.

SKELDON, R. (1986) On migration patterns in India during the 1970s. Popul. Dev. Rev. 12(4), 759-779.

Smita \& Chandna, R. C. (1991) M igration patterns in India. Popul. Geogr. 13(1-2), 31-52.

TAM, L. (1994) R ural-to-U rban M igration in Bolivia and Peru: A ssociation with Child M ortality, B reastfeeding Cessation, $\mathrm{M}$ aternal $\mathrm{C}$ are, and Contraception. Demographic and $\mathrm{H}$ ealth Survey Working Paper N 0. 8. M acro International Inc., Calverton, M aryland, USA.

Timeaus, I. M . \& L USH, L. (1995) Intra-urban differentials in child health. H Ith Trans. Rev. 5(2), 163-190.

U YANGA, J. (1983) Rural-urban migration and sickness/health care behaviour: a study of eastern Nigeria. Social Sci. M ed. 17(9), 579-583.

Zulkifli, S. N ., K hin M AW, U ., Y usof, K . \& L IN, W. Y. (1994) M aternal and child health in urban Sabah, M alaysia: A comparison of citizens and migrants. A sia Pacific J . publ. H Ith 7(3), 151-158. 